\title{
THE RESPIRATION OF SOME PLANKTONIC COPEPODS
}

\author{
By J. E. G. Raymont, B.Sc., A.M. \\ University College, Southampton \\ and D. T. Gauld, B.Sc., Ph.D. \\ Marine Station, Millport
}

(Text-figs. I, 2)

The respiratory rates of zooplankton organisms are of considerable interest, if only in so far as they permit an assessment of the metabolic requirements of the zooplankton, which forms a vital link in the economy of the sea. Yet very little information is available on the respiratory rates even of copepods, which usually comprise the bulk of a zooplankton community. Data exist only for a few species of copepods, and even then only for a few stages in the life histories of the species. The first measurements of the respiration of a selected species, as distinct from mixed plankton catches, were made by Marshall, Nicholls \& Orr (1935). They worked with Calanus finmarchicus (Gunner), adults (male and female) and Stage V. In 1939, Clarke \& Bonnet published a further series of measurements of the respiration of Stage V C. finmarchicus, giving figures slightly higher than those of Marshall et al. Zeuthen (I947) included some observations on copepods in his study of size and metabolic rates, but he determined the species of only a few of the animals he used.

In this paper the study of respiration in the Copepoda has been extended to a species much larger than Calanus, viz. Euchaeta norvegica Boeck, and to two smaller species, Centropages typicus Kroyer and C. hamatus (Lilljeborg), and in the two larger species, Calanus and Euchaeta, an additional copepodite stage has been included. In this and further papers a survey will be made of the respiration of the more important species of planktonic copepods, throughout their life histories and under varying environmental conditions. In this way, in time, a picture may be built up of the food requirements of the planktonic population in the sea.

The authors would like to thank Mr E. Ford, the Director of the Marine Station, Millport, for his interest and encouragement in the work.

\section{Material AND Methods}

Copepods were taken by townet in the Fairlie Channel, or off Garroch Head, both grounds within half an hour's run from the laboratory. The tow-nettings were well diluted for transport. In the laboratory, with the larger forms, 
vigorous specimens of the desired species and stage were picked out as soon as possible and put in jars of sea water filtered through Whatman No. I filterpapers. The labour of sorting individually large numbers of Centropages hamatus was very great; and for them, after the larger copepods and any possible predators such as medusae had been picked out, the townettings were well diluted with filtered sea water, and the Centropages picked out only as required. The jars were kept in a sink of running water where the temperature rarely changed by more than $\mathrm{I}^{\circ} \mathrm{C}$. in $24 \mathrm{hr}$. No copepods were used until at least the day following capture. An attempt was made not to use the same catch for more than 2 days, but unfortunately rough weather prevented fresh hauls being taken on several occasions, and, especially at the end of the experiments, copepods had to be used that had been captured 4-5 days before.

Respiration was measured manometrically, in Dixon-Haldane constant pressure respirometers, the apparatus being arranged as outlined by Dixon (1943). Clarke \& Bonnet (I939), who used this apparatus for their measurement of the respiration of Calanus, found that the presence or absence of $\mathrm{KOH}$ in the flasks had no effect on the readings observed. We were not satisfied on this point and $\mathrm{KOH}$ was always used in the annular cup in the neck of the flask. The respiration flasks were completely immersed in a bath of running water, as no means of maintaining a water-bath at constant temperatures below room temperature was readily available. It was possible by this means to keep the temperature well below $20^{\circ} \mathrm{C}$. The maximum range of temperature observed in the bath during any experiment was $0.5^{\circ} \mathrm{C}$., which was sufficiently constant to have no disturbing effect on the accuracy of the readings. The greatest disadvantage of this arrangement was the day-to-day variation in the temperature which fell more or less steadily from $19^{\circ} \mathrm{C}$. at the beginning of the series of experiments to $15.5^{\circ} \mathrm{C}$. towards the end.

The respirometers were attached to a Barcroft shaking-apparatus and shaken with an amplitude of $2 \mathrm{~cm}$. at a frequency of 100 per min. Contrary to the observation of Clarke \& Bonnet (1939), this shaking appeared to have no ill effect on the copepods, which survived well-only io out of a total of over 600 copepods used in the experiments died during the experiment, and the vast majority of them were alive and active the day following the experiment in which they had been used. However, in view of Clarke \& Bonnet's experience, copepods were never used a second time for normal experiments. After closing the respirometer taps, readings were made every $30 \mathrm{~min}$. for $3 \mathrm{hr}$. and the total change was converted to volume of dry gas at N.T.P. In the first nine measurements, where the respirometer taps were closed $5 \mathrm{~min}$. after the flasks had been attached, as recommended by Dixon, it was found that the first reading of the manometer, $30 \mathrm{~min}$. after the taps were closed, showed a very large change-sometimes two or three times that found for the subsequent $30 \mathrm{~min}$. periods. The period of equilibration was therefore increased to $15 \mathrm{~min}$., and the large initial change was eliminated. In the early experiments where the 
equilibration period was only 5 min., and an abnormally large change was recorded in the first $30 \mathrm{~min}$., the first half hour has been neglected and the calculations have been based on the last $2 \frac{1}{2} \mathrm{hr}$. experiment.

The respiration flasks usually contained $5 \mathrm{ml}$. of filtered sea water, but the number of copepods varied with their size-usually 2-5 Euchaeta, Io Calanus (adults, Stage V and Stage IV), 20-25 Centropages typicus and 50 C. hamatus.

For each experiment the copepods were picked out of the jars by eye, but when there was any doubt in identification they were checked under a lowpower microscope before being counted into the respiration flasks. In the experiment with $C$. hamatus, in order to save time and damage to the animals, they were sorted by eye only, but were fixed in formalin at the end of the experiment for checking and counting. Any animals which were to be measured after an experiment were similarly fixed and measured with an eyepiece micrometer.

\section{RESULTS}

In all, sixty-five separate determinations of respiration were made, and results are listed in Table I. In the table, the fifth column gives the amounts of oxygen in microlitres consumed by one copepod in I hr., for the temperature at which the experiment was made. A correction for temperature was made from the curve of respiration of Calanus with temperature, given by Marshall et al. The sixth column shows the data for respiration corrected to $\mathrm{I} 7^{\circ} \mathrm{C}$. Table II gives the mean values for each of these groups of observations, together with the standard deviation of the observations from their mean; the second figure in each pair is that obtained from the data corrected to $17^{\circ} \mathrm{C}$. In the discussion which follows reference will be made only to the figures corrected to $17{ }^{\circ} \mathrm{C}$.

More determinations were made on the respiration of Calanus Stage V than on any other form, and they include two small groups in which the conditions were changed. In the first special group (Exps. 36-39) the experiments were conducted in the dark, and in the second (Exps. 40-42) the respiration flasks were not shaken at all during the experiment. The group of experiments done in the dark give a mean respiration rate of $0.54 \mu \mathrm{l} . / \mathrm{cop} . / \mathrm{hr}$. as compared with $0.53 \mu \mathrm{l}$. cop. $/ \mathrm{hr}$. for those in the light; there is no significant difference between these two means ( $\left.d / \sigma_{d}=0 \cdot \mathrm{II}\right)$. This confirms the finding of Marshall et al. that the respiration of Calanus Stage $\mathrm{V}$ is not affected by light. The mean respiration rate when the respirometers were not shaken was $0.67 \mu \mathrm{l} . / \mathrm{cop}$. $/ \mathrm{hr}$.; this is significantly higher than that for the rest of the measurements $\left(d / \sigma_{d}=3 \cdot 14\right)$. The number of observations on Calanus adult males and on the stages of Euchaeta was severely limited by the difficulty of obtaining material; nevertheless, it was decided that the data obtained were worth including.

It has already been explained that, owing to the difficulty of identifying rapidly the stages of Centropages, almost all the experiments on $C$. hamatus 


\section{Table I. List of Experiments and Respiratory Rates Obtained}

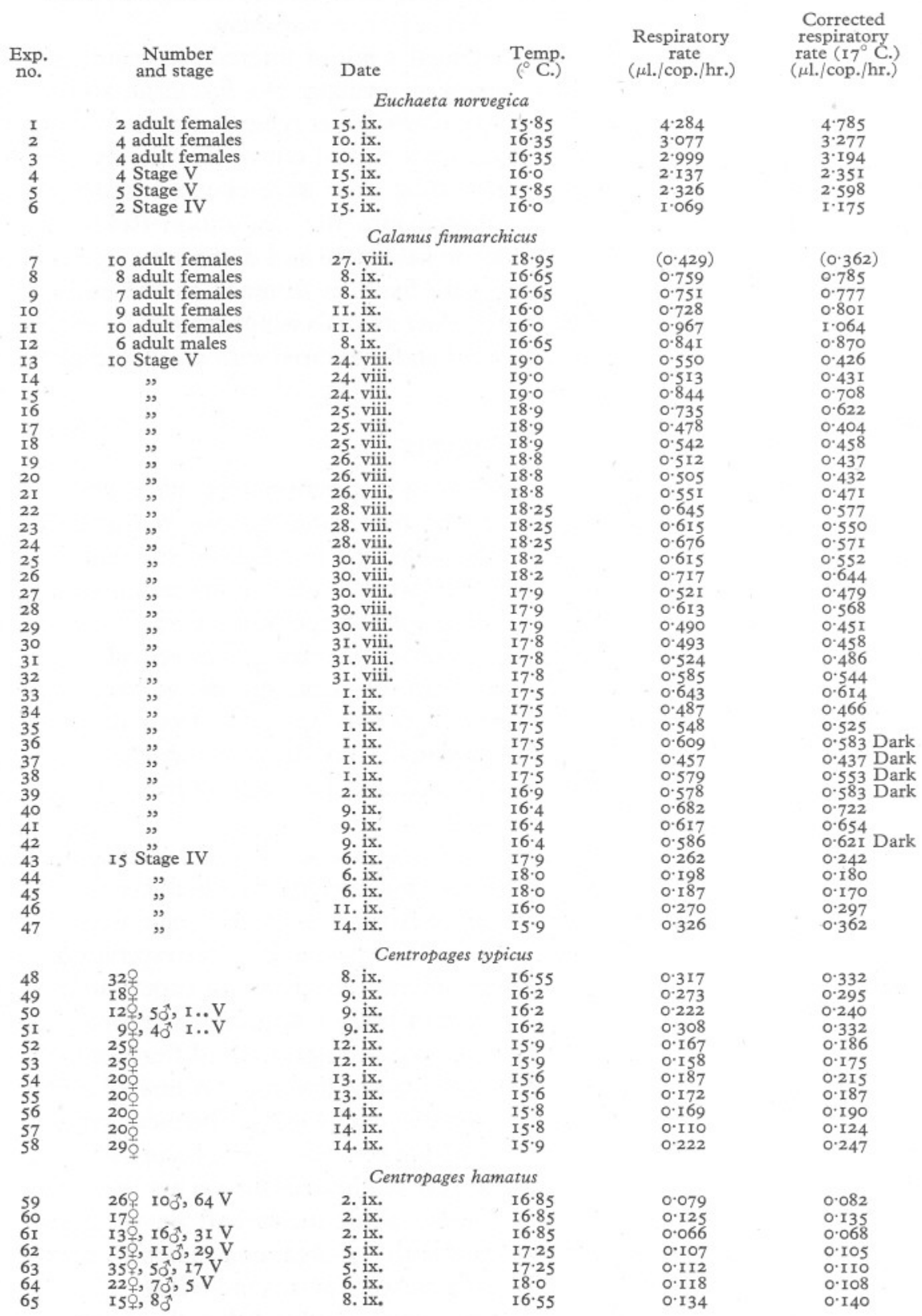


and the earlier ones on $C$. typicus were done on groups of animals which included adult males, females and Stage V. The data concerning C. typicus fall into two well-marked groups, but for reasons other than this mixing of adults and Stage V. Exps. 48-5I and 58 form one group in which there is a range in the rate of respiration from 0.24 to $0.33 \mu \mathrm{l}$. $/ \mathrm{cop}$. $/ \mathrm{hr}$. (mean =0.29), and Exps. 52-57 form a second group in which the rate of respiration is much lower, ranging from 0.12 to $0.22($ mean $=0.18)$. This difference in respiration rate cannot be explained as a consequence of a difference in the proportionate number of adult and Stage $\mathrm{V}$ animals used in the different experiments, since in Exps. 48, 49 and 58 of the first group, and in all the Exps. 52-57 of the second group, the animals were exclusively adult females, yet the rate of respiration was high in the first group and low in the second. Or again, within the first

\section{Table II. Mean Value of Respiratory Rate}

\begin{tabular}{|c|c|c|c|c|c|}
\hline \multirow[b]{2}{*}{$\begin{array}{c}\text { Species } \\
\text { Euchaeta norvegica }\end{array}$} & \multirow[b]{2}{*}{$\begin{array}{l}\quad \text { Stages } \\
\text { Adult }+ \\
\text { Adult } 0 \\
\text { V } \\
\text { IV }\end{array}$} & \multicolumn{2}{|c|}{$\begin{array}{l}\text { Respiratory rate } \\
\left(\mu 1 . \mathrm{O}_{2} / \text { cop./hr. }\right)\end{array}$} & \multicolumn{2}{|c|}{$\begin{array}{c}\text { Standard } \\
\text { deviation } \\
\sigma\end{array}$} \\
\hline & & $\begin{array}{c}\text { Observed } \\
4 \cdot 284 \\
3 \cdot 038 \\
2 \cdot 232 \\
1 \cdot 069\end{array}$ & $\begin{array}{c}\text { Corrected } \\
\text { to } 17^{\circ} \mathrm{C} \text {. } \\
4.785 \\
3.235 \\
2.474 \\
1.157\end{array}$ & $\begin{array}{c}\text { Observed } \\
\text { - } \\
\text { - }\end{array}$ & $\begin{array}{c}\text { Corrected } \\
\text { to } \mathrm{I}^{\circ} \mathrm{C} \text {. } \\
= \\
= \\
=\end{array}$ \\
\hline Calanus finmarchicus & $\begin{array}{l}\text { Adult 우 } \\
\text { Adult } 0 \\
\text { V (13-35) } \\
\text { V (36-39) } \\
\text { V (13-39) } \\
\text { V (40-42) } \\
\text { IV }\end{array}$ & $\begin{array}{l}0.80 I^{\star} \\
0.814 \\
0.578 \\
0.556 \\
0.578 \\
0.628 \\
0.249\end{array}$ & $\begin{array}{l}0.857 \\
0.870 \\
0.517 \\
0.539 \\
0.521 \\
0.666 \\
0.250\end{array}$ & $\begin{array}{l}0.1 \text { II } \\
0.089 \\
0.067 \\
0.090 \\
0.049 \\
0.057\end{array}$ & $\begin{array}{l}0.139^{\star} \\
0.080 \\
0.069 \\
0.076 \\
0.051 \\
0.081\end{array}$ \\
\hline Centropages typicus & $\begin{array}{l}\text { A }(48-5 \mathrm{I}, 58) \\
\mathrm{B}(52-57)\end{array}$ & $\begin{array}{l}0.268 \\
0.161\end{array}$ & $\begin{array}{l}0.289 \\
0.180\end{array}$ & $\begin{array}{l}0.031 \\
0.025\end{array}$ & $\begin{array}{l}0.044 \\
0.030\end{array}$ \\
\hline C. hamatus & & 0.106 & 0.107 & 0.025 & 0.026 \\
\hline
\end{tabular}

group itself, the rate of respiration in Exps. 50 and $5 \mathrm{I}$ in which animals were not all adult females was not significantly different from that in Exps. 48, 49 and 58 in which only adult females were present.

Originally it was thought that the lower rate of respiration in the second group of experiments might be due to starvation of the copepods used, with a consequent reduction in metabolism. In the first four, Exps. 48-5I, the measurements of respiration were all made on animals caught during the previous day, whereas in Exps. 52-57 carried out on I2-I4 September, the animals used had been caught on Io September. Those used in Exps. 52 and 53 had been kept for $48 \mathrm{hr}$. in filtered sea water and had therefore not fed for this period; those in Exps. 54 and 55 had been picked out of the diluted townet catches that had been standing in running water for $72 \mathrm{hr}$., and although there may have been some phytoplankton in the diluted townetting for the copepods to eat, the 
amount may well have been inadequate. The animals used in the four experiments, Exps. 52-55, were therefore transferred to a jar containing a thick suspension of a culture of Chlamydomonas and on the following day, after having been fed for $20 \mathrm{hr}$., the most active of these were picked out and used for Exps. 56 and 57. At the same time Exp. 58 was carried out with fresh animals picked out from a townetting taken the previous day (i.e. I3 September) and fed for $20 \mathrm{hr}$. The respiration rates in Exps. 56 and 57 were no different from those in Exps. 52-55; in Exp. 58 it was distinctly higher and agreed well with the rates observed in Exps. 48-5I (Table I). It is apparent therefore that starvation was not the cause of the lower respiration rate, or that, if starvation was the causative factor, one day's feeding in a rich suspension of food was insufficient for recovery.

It might be suggested that the lower rate of respiration was due to a size difference in the copepods, but it is unlikely that the animals caught on ro September were for any reason smaller than those caught at other times. In the first place they were caught in the same locality, and, in the absence of currents passing through the area, there is no reason to expect that they came from a population different from those caught on 9 September. Secondly, the two species of Centropages were always separated initially by the naked eye without difficulty, since the greater size of $C$. typicus clearly distinguished it from $C$. hamatus. It is shown later that the respiratory rate is roughly proportional to the square of the length. If the observed difference in the rate of the two groups of $C$. typicus were due to size, those copepods caught on Io September should have had a mean length of $c$. I mm., as compared with a mean length of $\mathrm{I} \cdot 25 \mathrm{~mm}$. for those caught on 9 September. But C. typicus of mean size $\mathrm{I} \mathrm{mm}$. would be no different in size from $C$. hamatus, and the normal separation of the two species on Io September without microscopical examination would have been impossible.

It is clear that the two groups of $C$. typicus did not differ appreciably in mean length, and it is more likely that marked differences in respiratory rate are in some way correlated with the handling and retention of the copepods in the laboratory. It may be suggested, and support for this suggestion will be given in a later section, that the lower rate of respiration is the more correct one and that Centropages takes longer to regain its normal respiratory rate after the excitement of capture and handling than does Calanus for which $24 \mathrm{hr}$. appears to be sufficient.

These differences in the respiratory rates of Centropages typicus adult females necessitated a careful scrutiny of the earlier observations in order to see whether such differences could be detected in any other species. Only one result was clearly anomalous, namely Exp. 7 with Calanus females (27 September) where the respiratory rate was $0.36 \mu \mathrm{l}$./cop. $/ \mathrm{hr}$. as compared with a mean for the other four experiments on adult females (Exps. 8-II) of $0.86 \mu \mathrm{l}$. $/ \mathrm{cop}$. $/ \mathrm{hr}$. Again the animals used in Exps. 7 had been kept for more than $24 \mathrm{hr}$. before the measure- 
ments were made. On the other hand, all the experiments done with Stage V Calanus from 28 August up to and including I September were done with animals taken from an unusually good townetting taken on 27 August, and no significant decline of the respiration rate is detectable in this group (cf. Table I, col. 5, Exps. 22-35). It may be incorrect, however, to compare Stage V Calanus with adult copepods. Stage $\mathrm{V}$ copepodites may be better able to maintain a constant metabolic rate under conditions of stress, for it must be remembered that Stage V copepodites obtained in late summer were part of an overwintering stock (cf. Marshall et al. 1934) which pass into deep water and possibly live at a lowered metabolic level (cf. Gross \& Raymont, I942).

TABle III. Length MEASUREMENTS

\begin{tabular}{|c|c|c|c|c|c|}
\hline \multirow{2}{*}{$\begin{array}{c}\text { Species and stage } \\
\text { (no. of observations) }\end{array}$} & \multicolumn{2}{|c|}{ Total length } & \multicolumn{3}{|c|}{ Cephalothorax } \\
\hline & Mean & $\sigma$ & Mean & & $\sigma$ \\
\hline \multicolumn{6}{|l|}{ Euchaeta norvegica: } \\
\hline Female (2) & $7 \cdot 45$ & 0.038 & $5 \cdot \mathrm{IO}$ & 0.0 & \\
\hline Male (8) & $6 \cdot 14$ & 0.259 & $4 \cdot 36$ & 0.184 & \\
\hline Stage V (5) & $5 \cdot 75$ & 0.148 & $4 \cdot 15$ & $0.12 I$ & \\
\hline \multicolumn{6}{|l|}{ Calanus finmarchicus: } \\
\hline Female (I9) & $3 \cdot 12$ & 0.1 I 8 & $2 \cdot 45$ & 0.091 & , \\
\hline Stage V (I9) & $2 \cdot 66$ & 0.225 & 2.06 & 0.175 & \\
\hline Stage IV (3I) & 2.03 & 0.138 & $I \cdot 63$ & 0.226 & \\
\hline \multicolumn{6}{|l|}{ Centropages typicus: } \\
\hline Female (37) & $I \cdot 86$ & O.III & $I \cdot 25$ & 0.095 & \\
\hline Male (8) & $I \cdot 74$ & 0.089 & $I \cdot 2 I$ & 0.040 & \\
\hline Stage V (2) & $I \cdot 66$ & 0.186 & $I \cdot 2 I$ & 0.074 & \\
\hline Stage IV (I) & $I \cdot 32$ & - & 0.95 & - & \\
\hline \multicolumn{6}{|l|}{ Centropages hamatus: } \\
\hline $\begin{array}{l}\text { Female (IO) } \\
\text { Male (8) }\end{array}$ & $\begin{array}{l}I \cdot 47 \\
I \cdot 29\end{array}$ & $\begin{array}{l}0.096 \\
0.089\end{array}$ & $\begin{array}{ll}I \cdot 06 \\
0.04\end{array}$ & $\begin{array}{l}0.097 \\
0.076\end{array}$ & \\
\hline Stage V (I) & $\mathrm{I} \cdot \mathrm{I} 6$ & 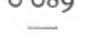 & 0.79 & $\underline{0.070}$ & \\
\hline
\end{tabular}

Table III gives the mean lengths of the groups of copepods measured. Two measurements are given for each group: (I) the length of the cephalosome and metasome, i.e. the 'cephalothorax'; and (2) the total length including the urosome. The advantages of measurements of the 'cephalothorax' are threefold: it is the bodily dimension that is easiest to measure accurately; it is the dimension most commonly used in measuring copepods; and thirdly, if the respiration rate is to be related to any power of a linear dimension, it will be more closely associated with some power of the length of the cephalothorax than with a power of the total length, since the cephalothorax makes up by far the greater part of the bulk of the animal. Our measurements agree reasonably well with previous measurements of copepods in the Clyde area (Marshall I933, 1949; Nicholls, I934).

\section{Discussion}

The measurements made of the respiratory rate of Calanus finmarchicus agree well with those determined previously by Marshall et al. (1935), and by Clarke \& Bonnet (I939). On both previous occasions measurements were 
given in $\mathrm{ml} . /$ Iooo cops./hr.; these are numerically the same when expressed in $\mu$ l. cop./hr. Marshall et al. made no observations at $17^{\circ} \mathrm{C}$., but their curve for the relationship between temperature and respiratory rate gives a value of $0.44 \mu \mathrm{l}$./cop./hr. for Calanus Stage V, which does not differ significantly from the mean value of our measurements, $0.52 \mu \mathrm{l} . / \mathrm{cop} . / \mathrm{hr} .\left(d / \sigma_{d}=\mathrm{I} \cdot 05\right)$. Clarke \& Bonnet's experiments at $\mathrm{I} 6.8^{\circ} \mathrm{C}$. give a rather higher respiration rate, $(0.80 \mu \mathrm{l}$./ cop./hr.), the difference from that given by the present observation being statistically significant $\left(d / \sigma_{d}=3 \cdot 4\right)$. However, the order of magnitude is the same, and in the present poor state of knowledge of the physiology of plankton, the agreement can be regarded as reasonably satisfactory. The respiration rates for male and female Calanus found by us were both higher than those given by Marshall et al., that for females (0.86 as compared with $0.66 \mu \mathrm{l} . / \mathrm{cop} . / \mathrm{hr}$.) being significantly so, but again the agreement is reasonably good. ${ }^{1}$

Zeuthen (1947) quotes one measurement of the respiration of Centropages hamatus, giving a mean respiration rate of $0.08 \mu \mathrm{l} . / \mathrm{cop} . / \mathrm{hr}$. at $\mathrm{I} 6^{\circ} \mathrm{C}$. This agrees fairly well with the measurements here recorded which have a mean of ०.II $\mu \mathrm{l}$./cop./hr. This agreement too becomes even closer when account is taken of the size of the animals: Zeuthen's copepod was $0.86 \mathrm{~mm}$. long (presumably total length) compared with the mean total length of $\mathrm{I} \cdot 30 \mathrm{~mm}$. for the $C$. hamatus given here.

Marshall et al. (I935) found marked falling off in respiration with time after capture, especially between the time of capture and $24 \mathrm{hr}$. later. Clarke \& Bonnet (I939) found no such decline but their results are hardly comparable, as they did not use animals until the day after capture-the practice followed in the experiments reported here. Zeuthen (I947), citing a single measurement of the respiratory rate of $C$. hamatus, found a decline during the course of his experiment. In the present series of observations, there was no very obvious decline during the course of individual experiments. However, if the mean oxygen consumption is calculated at the end of each $30 \mathrm{~min}$. period for the experiments with Calanus Stage V, the rate of consumption appears to fall (Fig. I), since the points for times shorter than the mean time ( $\mathrm{r} \cdot 75 \mathrm{hr}$.) lie above and two of those for longer times lie below the straight line drawn from the origin through the means ( $\mathrm{I} \cdot 75 \mathrm{hr}$. and I I $38 \mu \mathrm{l} \cdot \mathrm{O}_{2}$ consumed). But closer examination shows that only one of the means differs from the corresponding point on the straight line by as much as its standard error, and the deviation of this one, that for the second group, is less than three times its standard error so that the differences are insignificant. It is therefore improbable that there was any real falling off in the respiration rate during our experiments.

1 Comparison is made more difficult by the fact that the curve drawn by Marshall et al. showing the relationship between temperature and respiratory rate appears to be based on a single experiment, while different respiratory rates are given for other experiments at a given temperature. Thus the respiratory rates of female Calanus at $15^{\circ} \mathrm{C}$. is given on p. 8 as 0.57 , on p. 12 as about 0.70 (for normally saturated sea water), while on p. I5 a value of 0.74 is given for a temperature of only $12^{\circ} \mathrm{C}$. 
It is generally true that the respiratory rate of animals is related approximately to their surface area. Hence, since the copepods used in the experiments described above are all closely comparable in shape, some relationship may

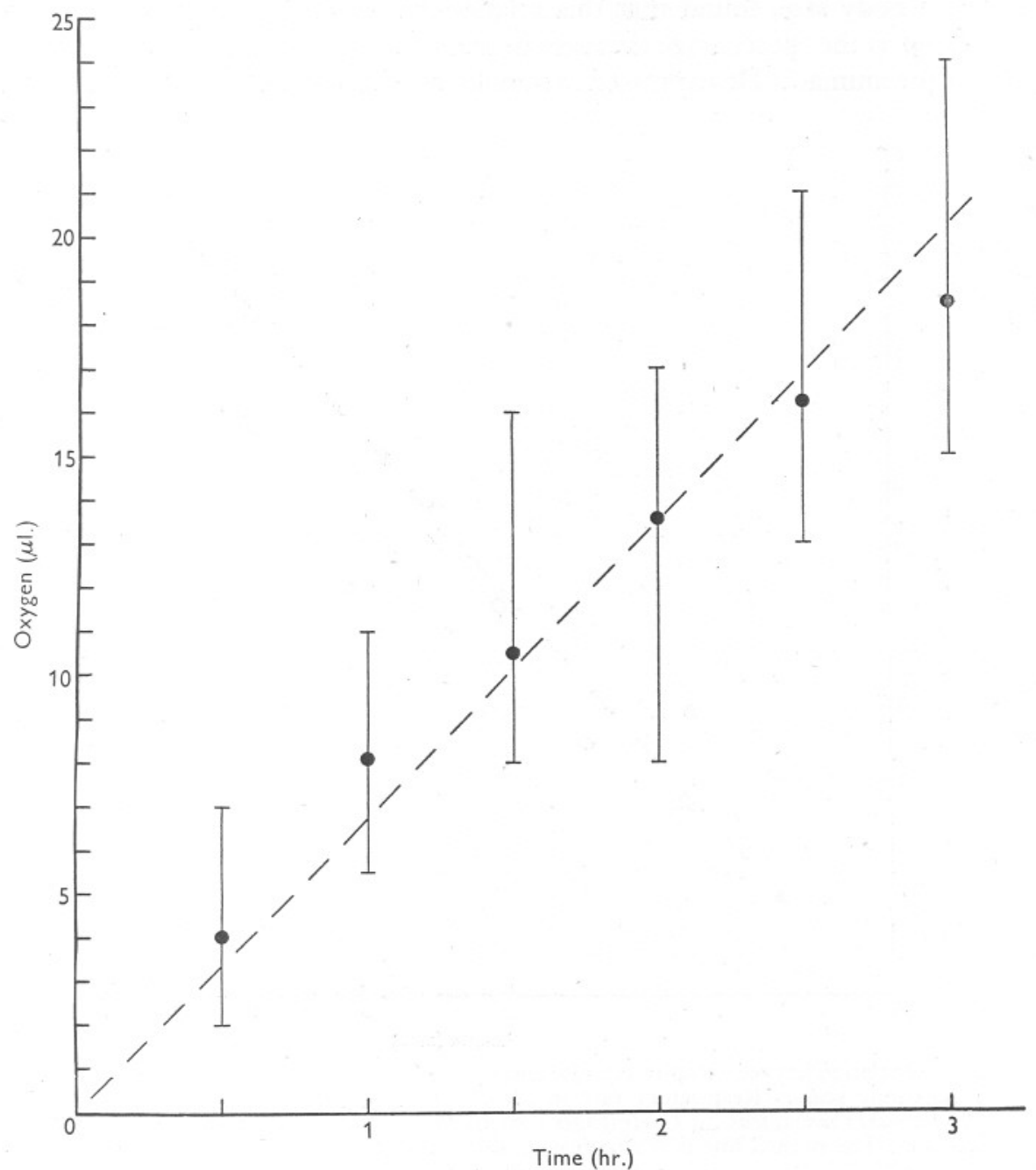

Fig. I. Oxygen consumption by ten copepods at half-hourly intervals after start of an experiment.

be expected between their respiratory rate and the square, or some power close to the square, of their length. In Fig. 2 the respiratory rate is plotted against the length, on logarithmic co-ordinates, and it can be seen at once that the observed values lie very nearly on a straight line. The calculated regression line of the logarithm of the respiratory rate $(R)$ on the logarithm of the length $(L)$ is

$$
\log R=2 \cdot 193 \log L-0.9278 \text {, }
$$


from which it can be seen that in these measurements the respiratory rate was related to the length to the power of $2 \cdot 19$.

Zeuthen (I947, p. 8I), in his analysis of the relationship between respiratory rate and body size, found that this relationship could be most satisfactorily expressed as the 'percentage decrease in metabolic rate at ten times magnification of the animal'. He expressed metabolic rate in terms of oxygen consumed

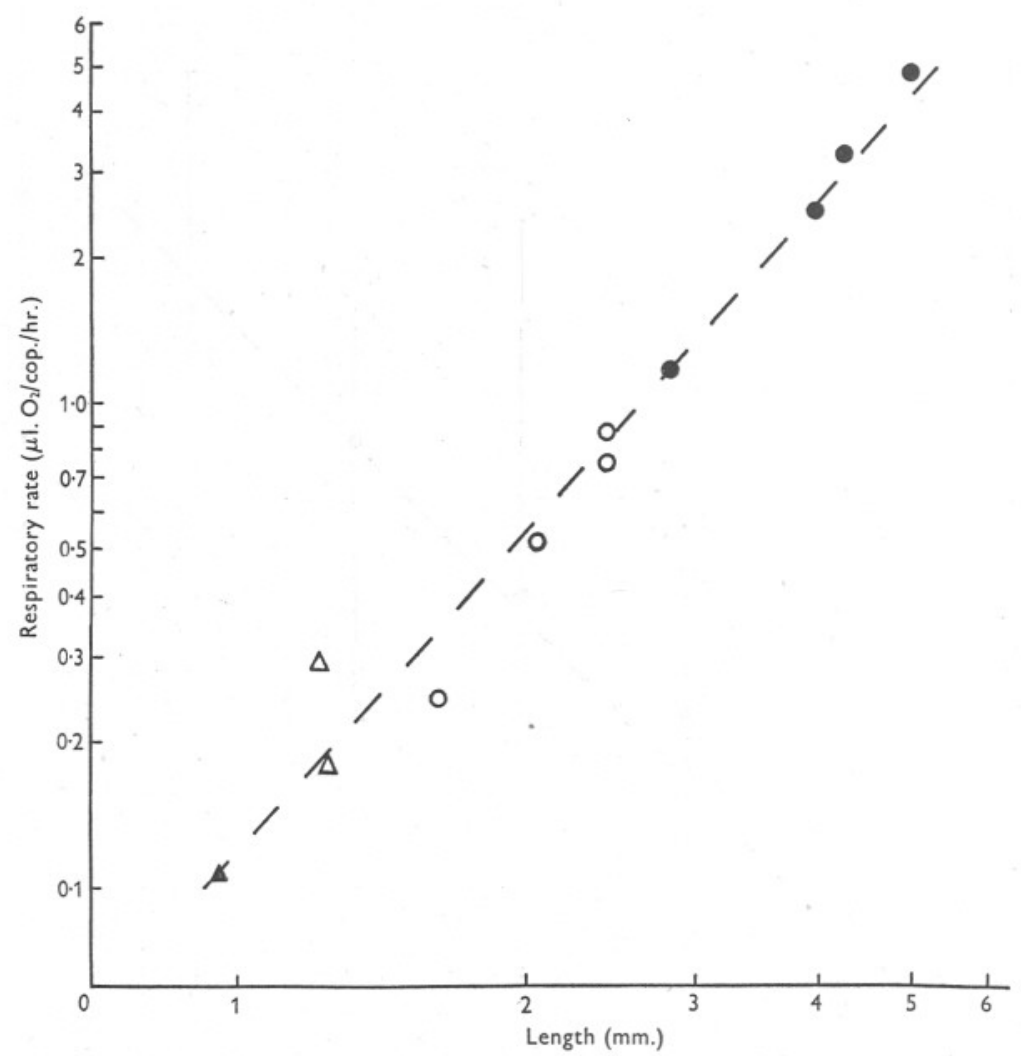

Fig. 2. The relation between respiratory rate and size of different copepods, plotted on a double logarithmic scale. (Respiratory rate in $\mu \mathrm{l}$. $\mathrm{O}_{2}$ per copepod per hour; length in $\mathrm{mm}$.) $O$, Euchaeta norvegica; $\triangle$, Centropages typicus; $\mathbf{0}$, Calanus finmarchicus; $\mathbf{\Lambda}$, Centropages hamatus. The pecked line is the regression line, given by

$$
\log R=2 \cdot 19 \log L-0.928 \text {. }
$$

per unit nitrogen content $\left(\frac{\mu 1 . \mathrm{O}_{2} \times \mathrm{IO}^{-2} / \mathrm{hr}}{\gamma \mathrm{N}}\right)$ or per unit of weight, and showed that for a ten times magnification of the body size, the percentage decrease declined fairly steadily from c. $52 \%$ for medium-sized animals (ro g.I000 g. wt.) to only c. $20 \%$ for small copepods. The percentage decrease for animals of the size range used in this present investigation he found to be 
30-40 \%. In the experiments described here no measurements of weights or nitrogen contents were made, but weight is usually closely proportional to the cube of the length for animals of similar shape so that a rough comparison with Zeuthen's results can be made by expressing metabolic rate as rate of oxygen consumption divided by the cube of the length.

In the measurements made above there are three pairs of figures from which percentage decrease in the metabolic rate for a ten-times magnification of size can be calculated. Euchaeta females are very nearly ten times the size (as given by the cube of the length) of Calanus females, Euchaeta males are just less than ten times the size of Calanus Stage V and Calanus Stage V are nearly ten times the size of Centropages hamatus. The decreases in metabolic rate (expressed by respiratory rate divided by the length cubed) found for these pairs are $30,35 \cdot 75$ and $49.75 \%$ respectively, with a mean of $38.5 \%$. The decrease in metabolic rate for a ten times increase in size calculated from the regression of respiratory rate on length given above is $46 \%$. These figures agree very well with Zeuthen's figure of $30-40 \%$ for animals of the range of size represented by the copepods used in the present experiment.

The difference between the respiratory rates of the two groups of experiments with $C$. typicus has been discussed above. The distribution of the observed points given in Fig. 2 suggests that the lower value might be the more correct one, or at least that corresponding to the figures found for the other species. The deviation of the higher value (0.29 $\mu \mathrm{l} . \mathrm{O}_{2} / \mathrm{cop} . / \mathrm{hr}$.) from the regression line

$$
\log R=2 \cdot 193 \log L-0.9278
$$

is 0.19 , twice the standard error of estimate (0.09), whereas that for the lower value (0. I $8 \mu \mathrm{l} . \mathrm{O}_{2} / \mathrm{cop}$. $/ \mathrm{hr}$.) is only 0.03. The agreement of the lower rather than the higher respiratory rate for $C$. typicus with those for the other species is made even clearer by calculating a regression omitting the higher value. This makes a slight but not clearly significant improvement in the correlation coefficient and gives regression equation

$$
\log R=2.302 \log L-0.9901 \text {. }
$$

The deviation of the higher respiratory rate from this line is more than three times the standard error of estimate, i.e. this value almost certainly differs from the group of values represented by this regression line, while the deviation of the lower value is less than half the standard error of estimate.

Several suggestions could be made to account for an enhanced respiratory rate in Centropages as found in Exps. 48-5I and 58-for instance, that C. typicus is excited more easily than other species by handling or by light, but in the absence of any information about the factors which might have produced the increase of the respiratory rate, further discussion is not profitable.

The question as to which of the two respiratory rates found for $C$. typicus 
represent the 'true' value leads to the wider question, namely how far the rates as determined for the other species (Calanus, Euchaeta, Centropages hamatus) are true for these copepods living under natural conditions in the sea. Any future discussion of nutritional requirements based on respiratory rates (cf. Pütter, I909) must imply that the metabolic rates determined in the laboratory are true for the copepods under natural conditions. The curve given by Marshall et al. (1935) for respiration and temperature would permit us to calculate approximately the respiration rates for the various temperatures at which the different species are living over the seasons of the year. But there are many other factors apart from temperature that might also affect respiration. Of these some attention has been given to such internal factors as sex and developmental stage. As regards environmental conditions, there are indications that light has little effect on Stage V Calanus (cf. also Marshall et al.), though no experiments were made using bright sunlight. However, the precise effects of light as well as of such factors as feeding, season, etc., must await further study.

There remains the very pertinent question as to how far the experimental conditions in a closed respirometer may modify the metabolic rate. The experiments on Calanus by Marshall et al. seemed to show that lowered $\mathrm{O}_{2}$ tension had little or no effect unless the concentration fell below about $3 \mathrm{ml} . \mathrm{O}_{2} / \mathrm{l}$. - a value which would never even be approached in our 3-hourly experiments. There is also the possible disturbing effect on metabolism of handling the animals. This would appear to be slight (with the possible exception of Centropages typicus) in view of the fact that no clear reduction in respiratory rate with time was observed in our experiments, and also since our results (for Calanus) agree very well with those of Marshall et al. who employed the Winkler technique where animals were left undisturbed for relatively much longer periods of time. From the results of a few experiments with Stage V Calanus (Table I, Exps. 40-42) where shaking was limited to a few minutes immediately prior to final reading of the manometers, it is apparent that shaking depressed the respiratory rate of the copepods. But no permanent injury appears to have been caused by it, since the great bulk of our experimental copepods were active and healthy after being in the respirometers, and indeed, if used for a second experiment, gave a result usually showing good agreement with the original determination. The shaking of the respirometers may have reduced respiration by interfering with the physical activity of the copepods in the respirometer flask rather than by injury of the animal.

It is obvious, of course, that we were measuring the respiratory rates of the copepods in a state of activity, but how far their activity in the respirometer corresponds to their normal activity in the sea is not easy to determine. In these measurements, as in those of Marshall et al. and Clarke \& Bonnet, the copepods were enclosed in a very small volume of water, of the order of I ml. per copepod, while in the sea the water in which the copepod is swimming is 
effectively infinite and its distance from its nearest neighbour is probably of the order of ten or possibly a hundred times as great as it is in the respirometer. In consequence the probability of contact with the walls of the respirometer or with other copepods is very much greater than it is nature. This repeated stimulus of contact may keep the copepods in a comparatively excited condition and this may produce a rise in the respiratory rate.

\section{SUMMARY}

The respiratory rates of four species of planktonic copepods were measured. In two of the species measurements were made with two copepodite stages, and with adult male and female specimens.

The rate for Calanus finmarchicus Stage V at $17^{\circ} \mathrm{C}$. was found to be $0.52 \mu \mathrm{l}$./cop./hr., a figure which agreed with previous measurements.

For all the species and stages studied the respiratory rate was found to be closely proportional to the length to the power of $2 \cdot 2$.

The relevance of such measurements to conditions in the sea is briefly discussed.

\section{REFERENCES}

Clarke, G. L. \& Bonnet, D. D., 1939. The influence of temperature on the survival, growth and respiration of Calanus finmarchicus. Biol. Bull. Woods Hole., Vol. 76, pp. $371-83$.

Dixon, M., I943. Manometric Methods. (Second Edition.) Cambridge University Press.

Gross, F. \& RAYmont, J. E. G., I942. The specific gravity of Calanus finmarchicus. Proc. Roy. Soc. Edin. B, Vol. 6I, pp. 288-96.

MARShall, S. M., I933. On the biology of Calanus finmarchicus. II. Seasonal variations in the size of Calanus finmarchicus in the Clyde Sea-Area. Fourn. Mar. Biol. Assoc., Vol. I9, pp. II I-38.

- 1949. On the biology of the small copepods in Loch Striven. Fourn. Mar. Biol. Assoc., Vol. 28, pp. 45-I22.

Marshall, S. M., Nicholls, A. G. \& OrR, A. P., 1934. On the biology of Calanus finmarchicus. Part V. Seasonal distribution, size, weight and chemical composition in Loch Striven in 1933, and their relation to the phytoplankton. Fourn. Mar. Biol. Assoc., Vol. 19, pp. 793-819.

1935. On the biology of Calanus finmarchicus. Part VI. Oxygen consumption in relation to environmental conditions. Fourn. Mar. Biol. Assoc., Vol. 20, pp. I-27.

Nicholls, A. G., I934. The developmental stages of Euchaeta norvegica, Boeck. Proc. Roy. Soc. Edin., Vol. 54, pp. 3I-50.

PütTER, A., I909. Die Ernährung der Wassertiere und der Stoffhaushalt der Gewässer. Jena.

ZeUTHEN, E., I947. Body size and metabolic rate in the animal kingdom with special regard to the marine micro-fauna. Compt. Rend. Lab. Carlsberg, Serr. Chim., Vol. 26, (No. 3), pp. I7-16r. 